\title{
Pursuing Effective Media Multitasking: An Effort of Managing Distractions in Digital Learning Classrooms
}

\author{
I Purwaningtyas \\ Study Program of English, Department of Languages and Literature \\ Faculty of Cultural Studies, Universitas Brawijaya, Malang, Indonesia \\ \{tyaz_wijaya@ub.ac.id\}
}

\begin{abstract}
The 21st-century skills refer to the teaching of digital literacy and the advanced learning techniques used in schools and colleges. E-Learning or digital technology is becoming more and more popular among the students. Unfortunately, technology also bring up some distractions. Most of the time, students are not focused on studying but rather are moving their attention back and forth between studying and various forms of technology. While doing multitasking, less information is being retained. Studying or doing homework while sitting in front of the TV, using social media or texting, makes the learning and retaining the information to be more complicated, increases the time it takes to complete homework, and may ultimately result in lower test scores (Rosen, 2016). In order to manage the distraction, there should be some effort in maintaining longer attention span of the students, gaining more concentration, and building more effective learning environment. This paper presents the use of more effective media multitasking such as establishing rules of using digital devices in classrooms, giving some extra time of using the devices purposively, incorporating the devices as learning media in the class, and also providing more engaging activities for the students. These activities will help the students to have clearer goal in studying, achieving better results, while also enjoying their time using the technology.
\end{abstract}

Keywords: Digital Learning, Technology Devices, Media Multitasking, Distractions

\section{INTRODUCTION}

Technological advancements are touching the education in ways never imagined before. The students have started adopting the new methods of technology in their studies now. They are fully equipped in learning faster and defining their future based on increased knowledge opportunity.

E-Learning has a massive presence in almost every field. Teachers today use different techniques like movie-clippings, advertisements, commentaries, drama and more to fulfil the need to educate the students. Language teaching is one such area where technology has taken over and improved the ways of learning. Technology has brought many impacts in education by introducing new ways of learning, by using methodologies such as adaptive learning, flipped classroom models, and massive open online courses. 
With the help of the technology students can identify their own learning needs, formulate their own learning goals, provide better time management in order to achieve goals and objectives, classify necessary learning resources to support their learning, implement learning strategies effectively, self-reflect on the learning process, pursue their targets, and evaluate the learning outcomes. Technological tools can boost students' abilities, revolutionize the way they work and think and give them new access to the world. (Peck and Dorricott, 1994)

There are some reasons to allow technology in the classroom, i.e; improves future orientation, gives instant access to knowledge, exciting way to learn, improve skills, gives chance to collaborate, reduces physical loads, improves self-confidence, and cost-effective.

The new technological development and the digital learning is improving the skills of the students. These skills are helping the students to prepare for their studies from the future perspective. It is making the students more aware and creative. E-learning methods and digital equipment are enhancing the skills through right course selection and better delivery.

The digital medium is an attractive method to retain the attention of the students. The students are finding it flexible to complete their assignment by maximizing their digital devices in the class. Technology in classroom and E-learning is making the students flexible. Now the students do not have to sit and study in a closed classroom. E-learning is making it simpler for them. They can easily find the model of learning that best suits their personalities. They can choose any e-learning method to study and complete their education. They have the option to sit at home and study through their laptop.

Despite of the many benefits technology has brought to recent classrooms, this advancement also offers great distractions for the students. While using personal laptops in class, there were also increasing disruptions to the teaching and learning process. Students were using their mobile phones and smart phones to send and receive text messages, emails, surfing the Internet and doing some checking. The term Checking might cover checking for text messages, checking Facebook updates, checking emails, checking Twitter, checking web sites, and checking whether my friends are checking them. This happens on a regular basis, and can typically be four or more times in one hour.

This study deals with the problems arise when students are having too many distractions in the classroom, what would be the impact in terms of grades of the students distracted by ICT devices How does an instructor struggle to compete with tablets, cell phones, netbooks, and text messaging? How do we manage the distractive equalities of technology in schools in order to have more efficient learning process.

\subsection{Pros and Cons to Allow Technology in the Classroom}

There is no doubts that e-learning is helping the students learn and do the tasks efficiently. Technology will help them complete their education easily. But, each coin has two sides. Therefore, now we will discuss the pros and cons of the e-learning-based education.

There are some pros of educational technologies. First is about the Flexibility. Online learning gives us full flexibility to accomplish our goals. Unlike traditional learning, the elearning is flexible for the students as well as for the teachers. We can access and learn anything we want, anytime we want. Second is about the Lower cost of the application. ELearning is a better option for the students who cannot afford going to extra classes. Other than the cost of a laptop and an online course, they generally do not have other expenses. Schools do not have to manage outdated libraries. The third is about the Mobility aspect of elearning. The e-learning medium allows the students to go mobile. Now they can learn from any location, even when they are not convenient place to study. e-Learning allows them to take full advantage of their time and get things done when you would not normally be able to. 
Nevertheless, there are also some cons of educational technologies. The Technical issues are the first problem. The students need to have devices that are compatible with the eLearning software. Moreover, the problem with Internet connection issues, software failure, device failure, and others are general challenges faced by the students. Next is about Health issues. Students should be careful not to suffer from a lot of health problems due to technological devices. They can suffer from health issues such as weak eyes, fatigue, stress, eye burn, back pains, headaches, and others. The last is about Distraction. Students, sometimes, use laptops and gadgets for things other than studying. They get indulged in social media websites, video channels, online games, and others.

The next discussion is specially attributed to Distractions. Simple but problematic element of the use of technology in the classroom.

\subsection{Distractions}

Classroom technologies such as smartphones, tablets, computers, and wireless internet access offer exciting opportunities to enhance and deepen the learning process. However, using technology in the classroom can also bring multiple distractions to students. They might think that these are not really distracting the process, in facts, these distractions are real. Without teachers' proactive supervision, students might access games, web pages, and social networking sites as they deliver instruction.

They argue that distraction actually arises from a conflict between two fundamental features of our brain: our ability to create and plan high-level goals versus our ability to control our minds and our environment as we take steps to complete those goals.

In a study conducted by Dr. Larry Rosen (2016), a psychology professor at California State University - Dominguez Hills, students were observed studying for a 15 minute period where they were told to learn something. He found was that students generally started to lose focus after about three minutes. On average, students only spent about 65 percent of the observation period in the condition of actually studying.

Dr. Rosen did another study where he surveyed high school students and asked them how often they switch from studying to doing something related to technology such as checking email, Facebook, texting or watching TV. Surprisingly, across all grade levels, $80 \%$ of students reported that they switch between studying and technology somewhat often to very often. Rosen calls this "Continuous Partial Attention," meaning that students are not focused on studying but rather are moving their attention back and forth between studying and various forms of technology in most of their time. As we might expect, students who were the most distracted generally had the most windows open on their computers. Students who were less distracted had higher scores and GPAs than students who switched back and forth fairly often and those who regularly check Facebook or text messages. Students who had strategies for studying also had higher GPAs according to Rosen's findings.

If a student is focused when doing their homework, they actually retain more of the information when it comes time to take a test on the same subject matter. This enables them to prepare studying for the test step by step and absorbing the information in small chunks. The strategy of chunking bits of information has been shown to be the most effective way to learn larger amounts of information and is a useful test preparation strategy. The result is much different when distraction happens. If a student does her homework while multitasking, that will result in less information being retained and therefore more time will be required for test preparation in order to achieve the same result.

Rubinstein and Meyer (2001), a psychology professor at the University of Michigan observed that under most conditions, the brain simply cannot perform two complex tasks simultaneously. Listening to a lecture while texting, or doing homework and being on 
Facebook - each of these tasks is very demanding, and each of them uses the same area of the brain, the prefrontal cortex.

In conclusion, the evidence is overwhelming. Studying or doing homework while sitting in front of the TV, using social media or texting, makes it more difficult to learn and retain the information, increases the time it takes to complete homework, and may ultimately result in lower test scores.

\subsection{Researches on Distractions Impacts the Classroom}

A study to examine the nature of in-class laptop use in a large lecture course and how that use is related to student learning was conducted by (Fried, 2008). In his research, he had students' complete weekly surveys of attendance, laptop use, and aspects of the classroom environment. Results revealed that students who used laptops in class spent considerable time multitasking and that the laptop use posed a significant distraction to both users and surrounding students. Most importantly, the level of laptop use was negatively related to several measures of student learning, including self-reported understanding of course material and overall course performance. As Fried explains "this research raises serious concerns about the use of laptops in the classroom. Students admit to spending considerable effective time during lectures using their laptops for things other than taking notes. More importantly, the use of laptops was negatively related to several measures of learning".

Another study by (Barkhuus, 2005) at the University of California San Diego investigated an undergraduate class of 141 students in computer science that were allowed to use laptops and other mobile devices via networked classroom technology known as "ActiveClass" to interact with their lecturers and ask questions anonymously. They observed the class for the last two thirds of the quarter in each lecture, inquired to students' use of ActiveClass and general classroom behaviour through a questionnaire and interviews with students. The observation resulted in the following: students preferred to use laptops in class for web surfing, writing projects and communication with peers. The questionnaires did confirm this as well; students with laptops in class did on average 1.6 different activities, doing activities such as surfing the internet, emailing or writing assignments, during a lecture. When comparing their laptop use to their self-reported level of attention, a difference emerges between attentive and less attentive students.

A study to examine the use of wireless laptops for promoting active learning in lecture halls was carried out by Barak, Lipson \&Lerman (2006). The study examined students' behaviour in class and their perceptions of the new learning environment throughout three continuous semesters. An online survey revealed that students have highly positive perceptions about the use of wireless laptops, but less positive perceptions about being actively participating in class. Class observations showed that the use of wireless laptops enables student-centered, hands-on, and exploratory learning, as well as meaningful studentto-student and student-to-instructor interactions and collaboration. However, findings also show that wireless laptops can become a source of distraction, if used for non-learning purposes. As noted by the researcher in their discussion, "however, the use of wireless laptops also has disadvantages. A fraction of the students (12\%) used their laptops for non-directed (i.e., non-learning) purposes, such as surfing the Web or sending e-mail messages. A similar part of students $(15 \%)$ indicated that the wireless laptops distracted their attention in class. This leads to the conclusion that wireless laptops should only be used in class only when the instructor requires the students to do so.

Every time we shift our attention, our brain has to reorient itself, further taxing our mental resources. According to (Jackson, 2008) in her book, Distracted that focuses on multitasking, "the brain takes time to change goals, remember the rules needed for the new task, and block 
out cognitive interference from the previous, still-vivid activity. Many studies have proven that switching between just two tasks can add substantially to our cognitive load, impeding our thinking and increasing the possibility that we will overlook or misinterpret simple information.

\section{RESEARCH METHOD}

This study is a qualitative research employing Field Research. Field Research examines the personal meanings of individuals' experiences and actions in the context of their social and cultural environment. This approach is considered to be appropriate to find out students' experience in having distractions in the classroom.

The investigation is carried out in the naturalistic environment where the phenomenon occurs. Methods of data collection include participant observation and depth interviews. Students are given a questionnaire to see the frequency and also the intensity of the distractions. The researcher also conducted an observation to ordinary classes experiencing distractions. The depth interview functions to collect data on the students' perception toward the distraction problems and also ways to overcome it. Analysis procedures consist of description, ordering or coding of data and displaying summaries of the data.

\section{RESULT AND DISCUSSION}

As the previous researches have shown, $80 \%$ of the students in the classroom are experiencing distractions in their daily classroom activities. While doing the activities for preparing the assignment, while listening to lectures, and also working with their groups, students were always mixing their activities with other non-studying matters. The most occurring activity is doing the checking on their social media. This happens because of the need to be always updated with the most recent events happened in their surrounding. Therefore, the activities of writing updated status, giving immediate responses, replying and also chatting with their friends are done continuously.

The effect of the distraction is indeed influential toward their concentration in accomplishing their projects. Distractions have led them into different focus and therefore caused longer time to finish the assignment. In the case of listening to lectures, distractions postponed them from understanding the concept they are learning. The researchers concluded that learning facts and concepts will be worse while they are distracted. Switching between tasks short circuits understanding will probably result in getting the tasks done, but losing its meaning.

In order to provide more meaningful and effective language teaching, teachers need to manage the classroom to be more lively and engaging. An important way to minimize distraction is by having digital tech rules and regulations. On the very first day of the semester, teachers need to distribute students a copy of classroom policies containing the allowed screen time and the instances, the circumstances where they can use their smartphones, laptops, and computers. These might include rules such as no smartphones are allowed when the teacher is conducting a lecture, devices should be put on silent/airplane mode before the start of the class, and that tablets should only be used during group exercises and note-taking sessions.

Another way is through purposively removing mobile distractions. If rules and incentives are not yet powerful enough, the next step is to ethically remove distractions from students' 
digital devices. Teachers need to use MDM (mobile device management) software which can be used to monitor and control students' mobile devices while they are inside the classroom and connected to a common wireless network. With this software, teachers can minimize student distractions by limiting applications, blanking screens, and controlling web browsing activities on student devices. A simpler way to ethically remove distractions from their devices would be like instructing students to put their mobile devices in airplane mode when they should not be browsing online. It is highly important that teacher establish this policies and commitment as a daily routine before the class begins.

The best classroom management tool is by Engaging lessons. As pointed out by Tom Daccord on Edudemic, when "the activity is engaging and challenging, there is an authentic audience, and prescribed time limits, students will not mess around. This is the most challenging part of being teachers. As teachers, this is a part of responsibility as well as a challenge to design the lessons by ensuring that the length and intensity of the discussion are appropriate to the range of the students' attention spans. Education World noted that they can only tolerate up to 30 minutes of continuous lecture. Any additional time should be dedicated to lively group activities. By implementing this strategy, students will not have more time doing things which do not support their learning.

\section{CONCLUSIONS}

In conclusion we can say that the use of technology is good for the education. The world is moving fast with technological advancements. Therefore, it has become imperative to ease the learning process to grow faster with the world. The use of technology also offers some distractions which are dangerous for the learning process. By having some ways to minimize distractions, like having rules to use digital devices, removing the devices when they are not specifically used in classroom, and also gaining more attention by applying more engaging lessons, teachers can create more lively situation and achieve better result at the end of the class. These will enable the students to have more sense for their own success in studying. The more powerful the goals they establish for themselves, and the more they feel ownership over those goals, the more they are able to pursue them in the face of both internal and external distractions.

\section{REFERENCES}

[1] Barak, M., Lipson, A. \&Lerman, S. (2006). Wireless laptops as means for promoting active learning in large lecture halls. Journal of Research on Technology in Education, 38(3), 245-263.

[2] Barkhuus, L. (2005). Bring your own laptop unless you want to follow the lecture: alternative communication in the classroom. ACM SIGGroup Conference on Supporting Group Work, 140-143.

[3] Daccord, Tom., (2014). Students Distracted by Screens?. https://edtechteacher.org $>$ students-distractions.

[4] Fried, C. B. (2008). In-class laptop use and its effects on student learning. Computers \& Education, 50(3), 906-914.

[5] Gazzaley, Adam and Rosen, Larry. (2016). The Distracted Mind. Penguin Random House.

[6] Jackson, M. (2008).Distracted: the erosion of attention and the coming dark age. (Amherst, NY: Prometheus, 2008), 79. 
[7] Kraushaar, J.M., \& Novak, D.C. (2010).Examining the effects of student multitasking with laptops during lecture.Journal of Information Systems Education, 21(2), 241-252.

[8] Peck, Kyle L., \& Dorricott, Denise. (1994). Why Use Technology. Realizing the Promise of Technology, 51(7). 11-14

[9] Rubinstein, J. S., Meyer, D.E., \& Evans, J.E. (2001). Executive Control of Cognitive Processes in Task Switching. Journal of Experimental Psychology: Human Perception and Performance, 27, 763-797 